Bull. Mater. Sci., Vol. 23, No. 4, August 2000, pp. 285-293. (C) Indian Academy of Sciences.

\title{
Dielectric properties of $\mathrm{NaF}-\mathrm{B}_{2} \mathrm{O}_{3}$ glasses doped with certain transition metal ions
}

\author{
M KRISHNA MURTHY, K S N MURTHY and N VEERAIAH* \\ Department of Physics, O.U. College of Science, Osmania University, Hyderabad 500 007, India \\ *Department of Physics, Nagarjuna University P.G. Centre, Nuzvid 521 201, India
}

MS received 8 February 2000; revised 10 May 2000

\begin{abstract}
Dielectric constant $\varepsilon$, loss $\tan \delta$, a.c. conductivity $\sigma$ and dielectric breakdown strength of $\mathrm{NaF}-\mathrm{B}_{2} \mathrm{O}_{3}$ glasses doped with certain transition metal ions (viz. $\mathrm{Cu}^{2+}, \mathrm{VO}^{2+}, \mathrm{Ti}^{4+}$ and $\mathrm{Mn}^{4+}$ ) are studied in the frequency range $10^{2}-10^{7} \mathrm{~Hz}$ and in the temperature range $30-250^{\circ} \mathrm{C}$. The values of $\varepsilon, \tan \delta, \sigma_{\text {a.c. }}$ are found to be the highest for $\mathrm{Cu}^{2+}$ doped glasses and the lowest for $\mathrm{Mn}^{4+}$ doped glasses. Activation energy for a.c. conduction and the value of dielectric breakdown strength are found to be the lowest for $\mathrm{Cu}^{2+}$ doped glasses and the highest for $\mathrm{Mn}^{4+}$ doped glasses. With the help of infrared spectra, increase in the values of $\varepsilon$ and $\tan \delta$ of these glasses with frequency and temperature are identified with space charge polarization. An attempt has been made to explain a.c. conduction phenomenon on the basis of quantum mechanical tunneling model (QMT)/carrier barrier hopping model.
\end{abstract}

Keywords. Dielectric properties; $\mathrm{NaF}-\mathrm{B}_{2} \mathrm{O}_{3}$ glasses; QMT model.

\section{Introduction}

The study of dielectric properties such as dielectric constant $\varepsilon$, loss $\tan \delta$, a.c. conductivity $\sigma_{\text {a.c. }}$ over a range of frequencies and temperatures and the dielectric break down strength of the glasses help in assessing their insulating character. Work along these lines was carried out in recent years on a variety of inorganic glasses by a number of researchers yielding valuable information (Mallawany 1994; Ravi Kumar and Veeraiah 1995, 1998; Ghosh and Chaudhari 1996; Nageswara Rao and Veeraiah 2000).

Alkali fluoro borate glasses are well known due to their variety of applications in phosphors, solar energy converters and in a number of electronic devices. These glasses are relatively moisture resistant, possess high mechanical strength when compared with the conventional alkali oxyborate glasses. Extensive studies on various properties like ESR studies (Sridhar et al 1995), optical properties (Sagar et al 1998, 1999) and thermoluminescence properties (Ramana and Sastry 1989) of various alkali fluoro borate glasses doped with different transition and rare earth metal ions are available. Quite recently we have reported the results of our studies on various elastic, optical and some insulating properties of lithium, potassium borate glasses doped with certain rare earth ions (Kumar and Veeraiah 1999; Sagar et al 1999). These studies have yielded valuable information regarding the mechanical and insulating strength of these glasses. In

*Author for correspondence this investigation we have attempted to study the various insulating properties like dielectric properties, dielectric breakdown strength of $\mathrm{NaF}-\mathrm{B}_{2} \mathrm{O}_{3}$ glasses. Interesting changes in the insulating properties of these glasses are expected when they are doped with different transition metal ions like $\mathrm{Cu}^{2+}, \mathrm{VO}^{2+}, \mathrm{Ti}^{4+}$ and $\mathrm{Mn}^{4+}$, in view of the fact that these ions possess different field strengths in $\mathrm{NaF}-\mathrm{B}_{2} \mathrm{O}_{3}$ glass network. To have a comprehensive understanding over the influence of different transition metal ions on insulating character of sodium fluoro borate glasses, we have undertaken a systematic investigation on dielectric constant $\varepsilon, \operatorname{loss} \tan \delta$ and a.c. conductivity $\sigma$ in the frequency range $10^{2}-10^{7} \mathrm{~Hz}$ and in the temperature range $30-250^{\circ} \mathrm{C}$ and also the dielectric break down strength in the air medium at room temperature.

\section{Experimental}

For the present investigation, the following compositions of the $\mathrm{NaF}-\mathrm{B}_{2} \mathrm{O}_{3}$ (all in mol\%) were chosen: glass $\mathrm{A}$ (pure): $40 \mathrm{NaF}-60 \mathrm{~B}_{2} \mathrm{O}_{3}$, glass $\mathrm{B}: 40 \mathrm{NaF}-59 \mathrm{~B}_{2} \mathrm{O}_{3}: 1 \mathrm{CuO}$, glass C: $40 \mathrm{NaF}-59 \mathrm{~B}_{2} \mathrm{O}_{3}: 1 \mathrm{~V}_{2} \mathrm{O}_{5}$, glass D: $40 \mathrm{NaF}-59 \mathrm{~B}_{2} \mathrm{O}_{3}: 1 \mathrm{TiO}_{2}$ and glass E: $40 \mathrm{NaF}-59 \mathrm{~B}_{2} \mathrm{O}_{3}: 1 \mathrm{MnO}_{2}$. Appropriate amounts of Analar grade reagents of $\mathrm{NaF}, \mathrm{H}_{3} \mathrm{BO}_{3}, \mathrm{CuO}, \mathrm{V}_{2} \mathrm{O}_{5}$, $\mathrm{TiO}_{2}$ and $\mathrm{MnO}_{2}$ were thoroughly mixed and melted in a platinum crucible at $950^{\circ} \mathrm{C}$ for about $1 \mathrm{~h}$ until a bubble free liquid was formed. The resultant melt was then cast in a brass mould and subsequently annealed at $300^{\circ} \mathrm{C}$. The amorphous state of the glasses was checked by X-ray diffraction spectrum recorded on SIEFERT Diffractometer 
Model SO DEBYE FLUX-2002. Glass transition temperatures of these glasses were determined from the differential scanning calorimetric studies using TA Instruments DSC 2010 Differential Scanning Calorimeter. The infrared transmission spectra of these glasses in $\mathrm{KBr}$ matrices were recorded in the range $200-4000 \mathrm{~cm}^{-1}$ using a PerkinElmer 1600 IR spectrophotometer. The samples were then ground and finely polished. The final dimensions of the samples were about $1 \times 1 \times 0.2 \mathrm{~cm}$. The density $d$ of the glasses was determined to an accuracy of 0.001 by standard Archimedes' principle using xylene (99.99\% pure) as the buoyant liquid. A thin coating of silver paint was applied (to the larger area faces) on either side of the samples to serve as electrodes. The dielectric measurements were made on LCR Meter (Hewlett-Packard Model4263B) in the frequency range $10^{2}-10^{5} \mathrm{~Hz}$ and on Radart Q-Meter in the frequency range $10^{5}-10^{7} \mathrm{~Hz}$. The dielectric break down strength of all the glasses was determined at room temperature in air medium using a high a.c. voltage break down tester (ITL Model AAH-55) operated with an input voltage of $250 \mathrm{~V}$ at a frequency of $50 \mathrm{~Hz}$; it was ensured that all the glasses used for this study were of identical thicknesses.

\section{Results}

The differential scanning calorimetric recordings from which the glass transition temperatures $\left(T_{\mathrm{g}}\right)$ for sodium fluoro borate glasses doped with different transition metal oxides are determined, are shown in figure 1. Figure 2 presents infrared transmission spectra of all the glasses; the spectra show three main groups of bands in the frequency regions $680-710,800-1200$ and $1200-1600 \mathrm{~cm}^{-1}$. Other weak bands observed at various frequencies for these glasses are shown in the same figure. From the measured values of density $d$ and calculated average molecular weight $\bar{M}$, various physical parameters such as dopant metallic ion concentration $N_{\mathrm{i}}$, mean dopant ion separation distance $R_{\mathrm{i}}$, and field strength $F_{\mathrm{i}}$ which are useful for understanding insulating character of these glasses are evaluated and presented in table 1 .

The dielectric constant $\varepsilon$ of pure sodium fluoro borate glasses $\left(40: 60 \mathrm{~mol} \%\right.$ of $\mathrm{NaF}-\mathrm{B}_{2} \mathrm{O}_{3}$ ) at $30^{\circ} \mathrm{C}$ and at $10^{6} \mathrm{~Hz}$ is found to be 7.2 and is almost independent of frequency; when transition metal ions are added into these glasses, $\varepsilon$ values at room temperature are found to decrease with increasing frequency (table 2). The dielec$\operatorname{tric} \operatorname{loss}(\tan \delta)$ variation with frequency at room temperature for all these glasses has also exhibited similar behaviour.

The variation of dielectric constant and loss with temperature at different frequencies for all the glasses show $\varepsilon$ and $\tan \delta$ values increase considerably at low frequencies and in high temperature region; figure 3 presents the variation of dielectric constant with temperature at different frequencies for glass $\mathrm{B}\left(\mathrm{Cu}^{2+}\right.$ doped glasses). The comparison of variation of dielectric constant with
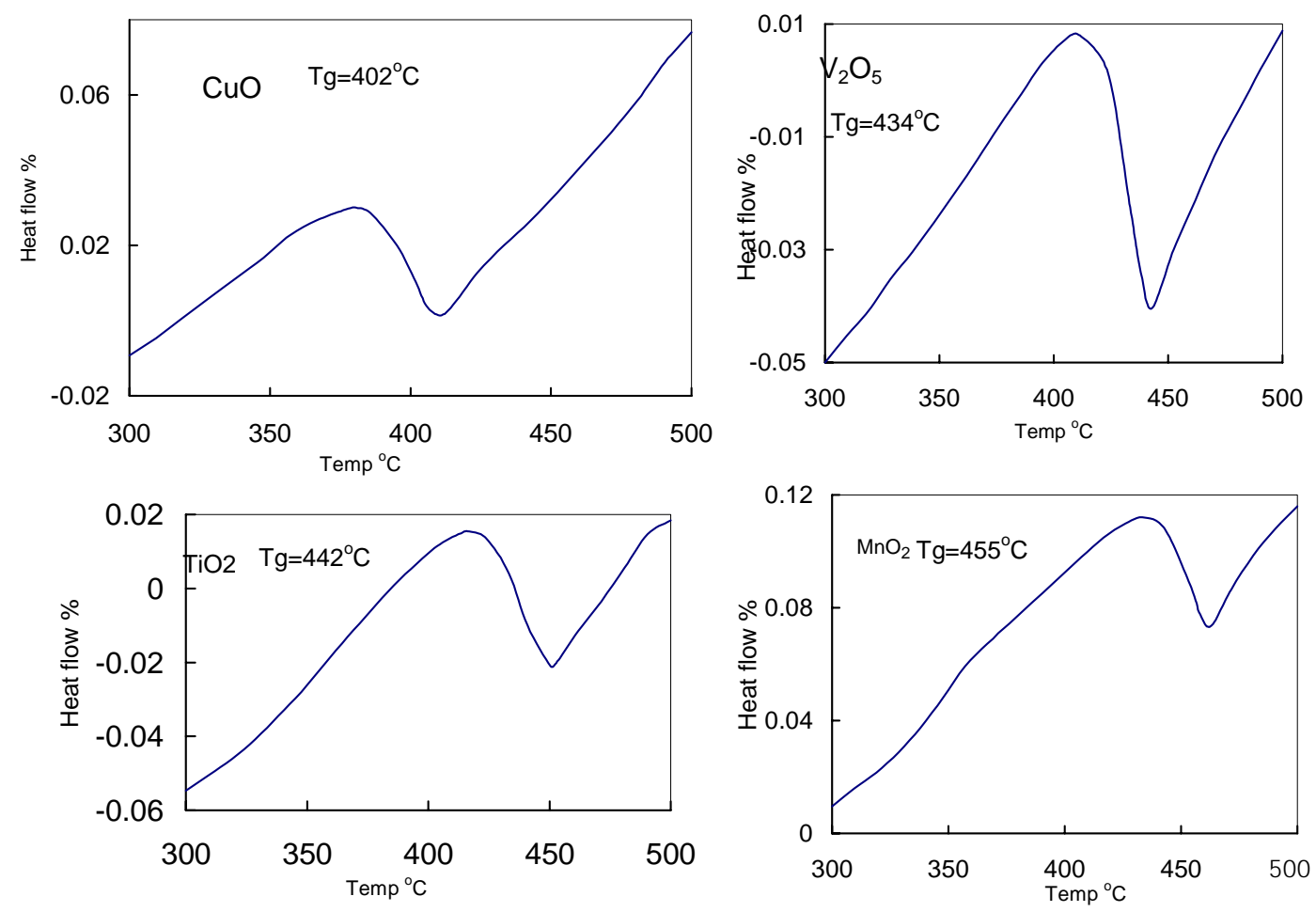

Figure 1. DSC curves for $\mathrm{NaF}-\mathrm{B}_{2} \mathrm{O}_{3}$ glasses doped with different transition metal oxides. 
temperature for sodium fluoro borate glasses doped with different transition metal ions at $1 \mathrm{kHz}$ is shown in figure 4; the rate of increase of $\varepsilon$ with temperature is found to be highest for $\mathrm{CuO}$ doped glasses (followed by glasses $\mathrm{C}, \mathrm{D}$ and E) and lowest for pure glasses. The variation of dielectric loss with temperature has also exhibited similar behaviour; however, the variation of dielectric loss with temperature at different frequencies for glass D is shown in figure 5 and a comparison in figure 6 . The summary of data on the dielectric constant and dielectric loss for all the glasses is presented in table 2 .

The a.c. conductivity $\sigma$ is calculated at different temperatures using the equation

$$
\sigma=\omega \varepsilon_{0} \varepsilon \tan \delta
$$

(where $\varepsilon_{0}$ is the vacuum dielectric constant) for different frequencies and the plots of $\log \sigma$ against $1 / T$ are shown in figure 7 for glass $\mathrm{C}$ and at $100 \mathrm{kHz}$ for all glasses.

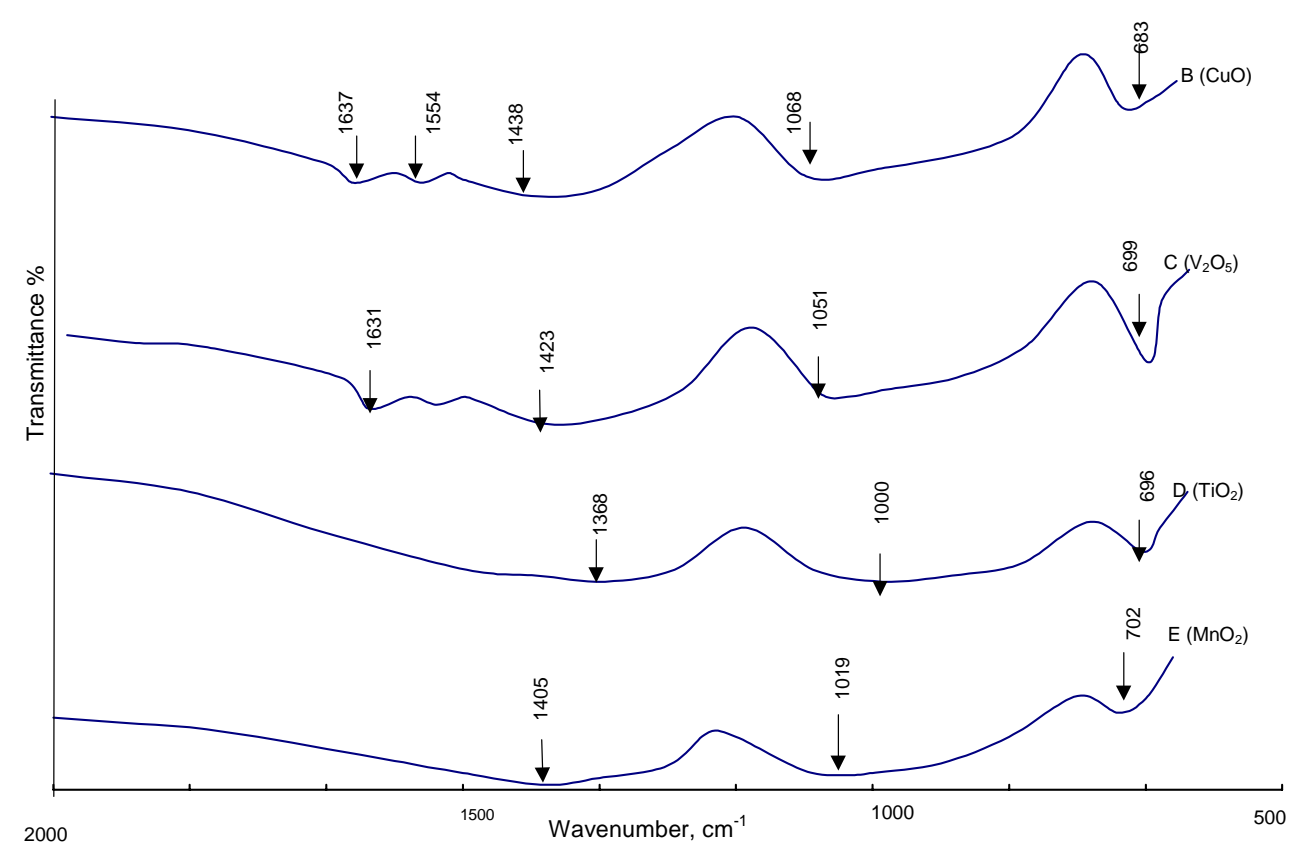

Figure 2. IR spectra of $\mathrm{NaF}-\mathrm{B}_{2} \mathrm{O}_{3}$ glass doped with different transition metal oxides.

Table 1. Various physical properties of $\mathrm{NaF}-\mathrm{B}_{2} \mathrm{O}_{3}$ : TMO glasses.

\begin{tabular}{lcccc}
\hline Property & Glass B $\left(\mathrm{Cu}^{2+}\right)$ & Glass C $\left(\mathrm{VO}^{2+}\right)$ & Glass D $\left(\mathrm{Ti}^{4+}\right)$ & Glass E $\left(\mathrm{Mn}^{4+}\right)$ \\
\hline Density $d\left(\mathrm{~g} / \mathrm{cm}^{3}\right)$ & $2 \cdot 06$ & $2 \cdot 25$ & $2 \cdot 28$ & $2 \cdot 19$ \\
Glass transition temp. $\left(T_{\mathrm{g}},{ }^{\circ} \mathrm{C}\right)$ & 402 & 434 & 442 & 455 \\
Average molecular weight $(\bar{M})$ & $58 \cdot 66$ & $59 \cdot 64$ & $58 \cdot 74$ & $58 \cdot 67$ \\
Doped metal ion concentration & & & & $2 \cdot 31$ \\
$\quad N_{\mathrm{i}}\left(10^{22}\right.$ ions $\left./ \mathrm{cm}^{3}\right)$ & $2 \cdot 12$ & $2 \cdot 21$ & 3.33 & 3.51 \\
Inter-ionic distance $R_{\mathrm{i}}(\AA)$ & 3.61 & $3 \cdot 55$ & 3.50 & 1.42 \\
Polaron radius $R_{\mathrm{p}}(\AA)$ & 1.46 & 1.43 & 1.41 & 1.99 \\
Field strength $F_{\mathrm{i}}\left(10^{16} \mathrm{~cm}^{-2}\right)$ & 0.95 & 2.43 & $2 \cdot 00$ & \\
\hline
\end{tabular}

Table 2. Summary of data on dielectric constant and loss.

\begin{tabular}{|c|c|c|c|c|c|c|}
\hline \multirow[b]{2}{*}{ Glass } & \multicolumn{2}{|c|}{$\varepsilon$ at $1 \mathrm{kHz}$} & \multicolumn{2}{|c|}{$100 \mathrm{kHz}$} & \multicolumn{2}{|c|}{$\tan \delta$ at $10 \mathrm{kHz}\left(\times 10^{-3}\right)$} \\
\hline & R.T. & $250^{\circ} \mathrm{C}$ & R.T. & $250^{\circ} \mathrm{C}$ & R.T. & $250^{\circ} \mathrm{C}$ \\
\hline Glass A & $8 \cdot 75$ & $22 \cdot 86$ & $7 \cdot 28$ & $12 \cdot 13$ & $3 \cdot 7$ & $11 \cdot 0$ \\
\hline Glass B & $14 \cdot 8$ & $56 \cdot 10$ & $7 \cdot 90$ & $22 \cdot 27$ & $8 \cdot 0$ & $34 \cdot 0$ \\
\hline Glass C & $12 \cdot 5$ & $45 \cdot 02$ & $7 \cdot 62$ & $16 \cdot 00$ & $7 \cdot 5$ & $28 \cdot 0$ \\
\hline Glass D & $11 \cdot 2$ & $36 \cdot 20$ & $7 \cdot 41$ & $13 \cdot 98$ & $6 \cdot 5$ & $26 \cdot 0$ \\
\hline Glass E & $9 \cdot 0$ & $30 \cdot 10$ & $7 \cdot 32$ & $13 \cdot 50$ & $6 \cdot 0$ & $15 \cdot 0$ \\
\hline
\end{tabular}


From these plots, the activation energy for a.c. conduction in the high temperature region over which a near-linear dependence of $\log \sigma$ with $1 / T$ could be observed, is calculated and presented in table 3 . This activation energy is found to be highest for pure $\mathrm{NaF}-\mathrm{B}_{2} \mathrm{O}_{3}$ glasses and decreases from glass $\mathrm{E}$ to $\mathrm{B}$.

\section{Discussion}

The properties of glasses depend not only on their composition, but also to a considerable degree on their structure.
Deep and important changes in the properties of glass can occur as a result of structural transformation (Ravi Kumar et al 1997). $\mathrm{NaF}-\mathrm{B}_{2} \mathrm{O}_{3}$ glasses doped with various metal ions have complex composition and an admixture of network formers and modifiers. $\mathrm{B}_{2} \mathrm{O}_{3}$ is a well known network former with $\mathrm{BO}_{3}$ structural units. The presence of $\mathrm{BO}_{4}$ units is evident in these glasses from the study of the IR spectra. The infrared spectra of $\mathrm{NaF}-\mathrm{B}_{2} \mathrm{O}_{3}$ glasses show three groups of absorption bands as mentioned earlier; (i) in the region $1200-1600 \mathrm{~cm}^{-1}$, due to stretching relaxation of the $\mathrm{B}-\mathrm{O}$ bond of the trigonal $\mathrm{BO}_{3}$ units (more specifically $\mathrm{B}_{3}\left(\mathrm{O}_{3}\right)^{-}$vibrations), (ii) in the region

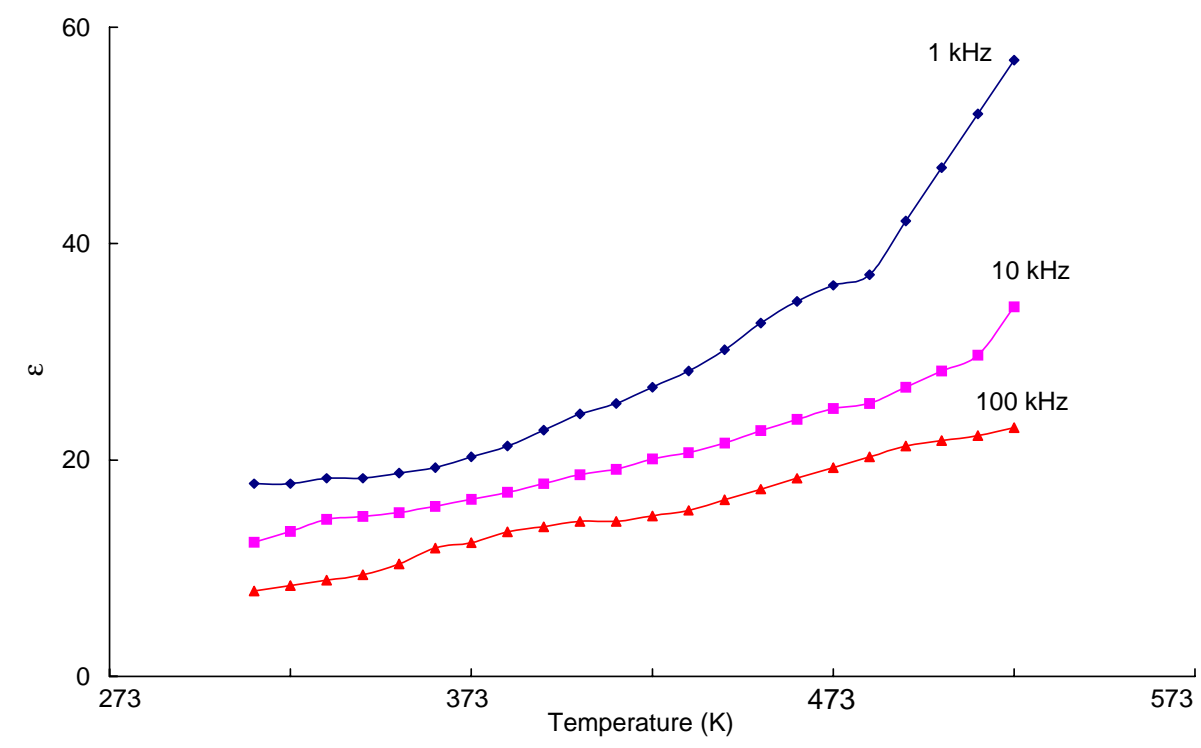

Figure 3. Variation of dielectric constant with temperature at different frequencies for $\mathrm{CuO}$ doped $\mathrm{NaF}-\mathrm{B}_{2} \mathrm{O}_{3}$ glasses (glass $\mathrm{B}$ ).

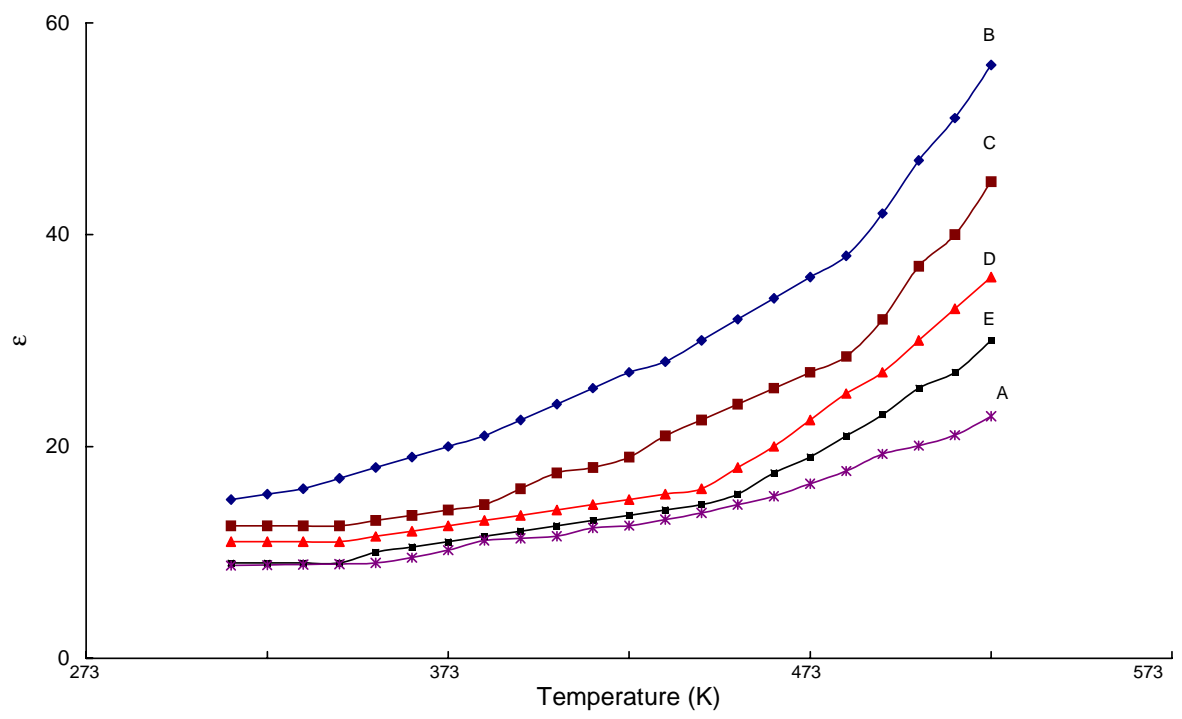

Figure 4. Variation of dielectric constant with temperature at $1 \mathrm{kHz}$ for $\mathrm{NaF}-\mathrm{B}_{2} \mathrm{O}_{3}$ glasses doped with different transition metal oxides: A-Pure, B-CuO, C- $\mathrm{V}_{2} \mathrm{O}_{5}, \mathrm{D}-\mathrm{TiO}_{2}$ and E- $\mathrm{MnO}_{2}$. 
$800-1200 \mathrm{~cm}^{-1}$, due to $\mathrm{B}-\mathrm{O}$ bond stretching of the tetrahedral $\mathrm{BO}_{4}$ units and (iii) in the region $680-710 \mathrm{~cm}^{-1}$ due to the bending of $\mathrm{B}-\mathrm{O}-\mathrm{B}$ linkages in the borate network. When modifier metal oxides are introduced into the glass network the intensity of the bands in the second group is found to be less for $\mathrm{CuO}$ doped glasses and highest for $\mathrm{MnO}_{2}$ doped glasses; further it is also observed that the frequency of this band is shifted towards higher frequencies (clearly seen) from glass $\mathrm{C}$ to $\mathrm{E}$. These observations indicate the presence of low concentration of $\mathrm{BO}_{4}$ units in $\mathrm{CuO}$ doped $\mathrm{NaF}-\mathrm{B}_{2} \mathrm{O}_{3}$ glass network (Khalifa and Elhadi 1996; Ahmed and Abd-Elshafi 1998) when compared with the other glasses.
The metal oxide modifiers enter the glass network by breaking up tetrahedral bonds (the oxygen of metal oxides break the local symmetry while metal ions occupy interstitial position) of $\mathrm{BO}_{4}$ units and introduce coordinated defects known as dangling bonds in these glasses. The increase in the concentration of these bonding defects in the glass network may increase with increase in the size of the dopant ion. This is evidenced from IR spectra as discussed above.

Variation of $\varepsilon$ and $\tan \delta$ with temperature is the highest for glass $\mathrm{B}$ in which the modifier present is $\mathrm{CuO}$. This indicates a greater degree of lattice distortion in $\mathrm{NaF}-$ $\mathrm{B}_{2} \mathrm{O}_{3}$ glasses containing $\mathrm{CuO}$ among all other glasses and

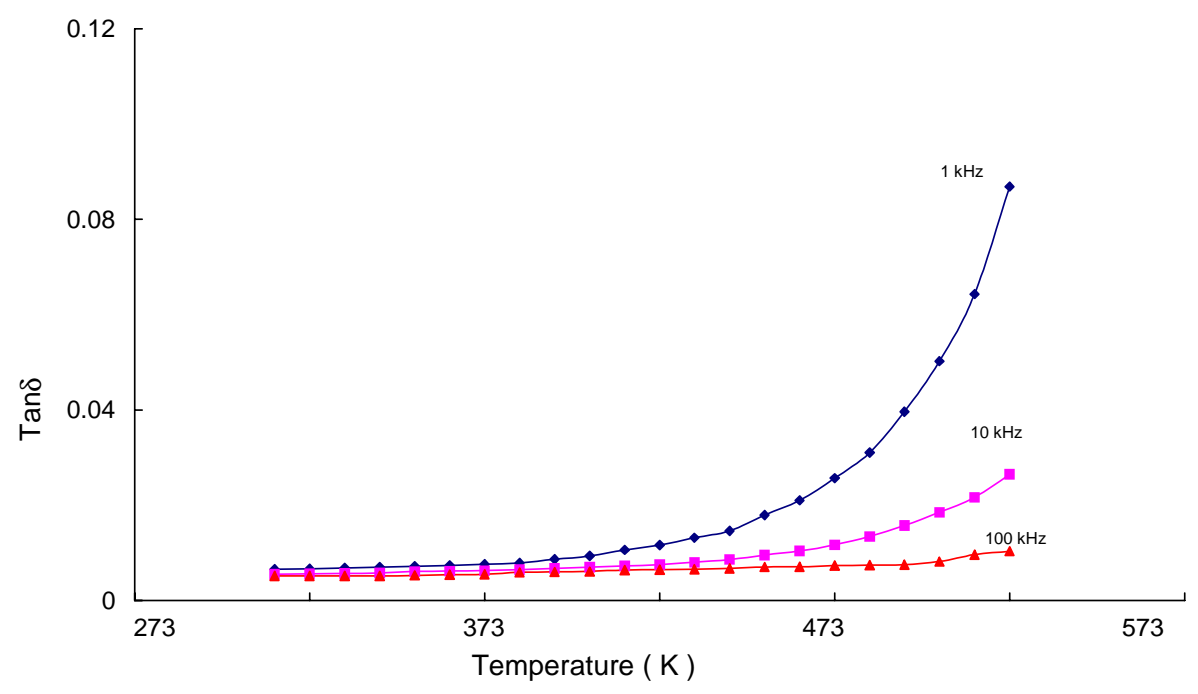

Figure 5. Variation of dielectric loss with temperature at different frequencies for $\mathrm{TiO}_{2}$ doped (glass D) $\mathrm{NaF}-\mathrm{B}_{2} \mathrm{O}_{3}$ glasses.

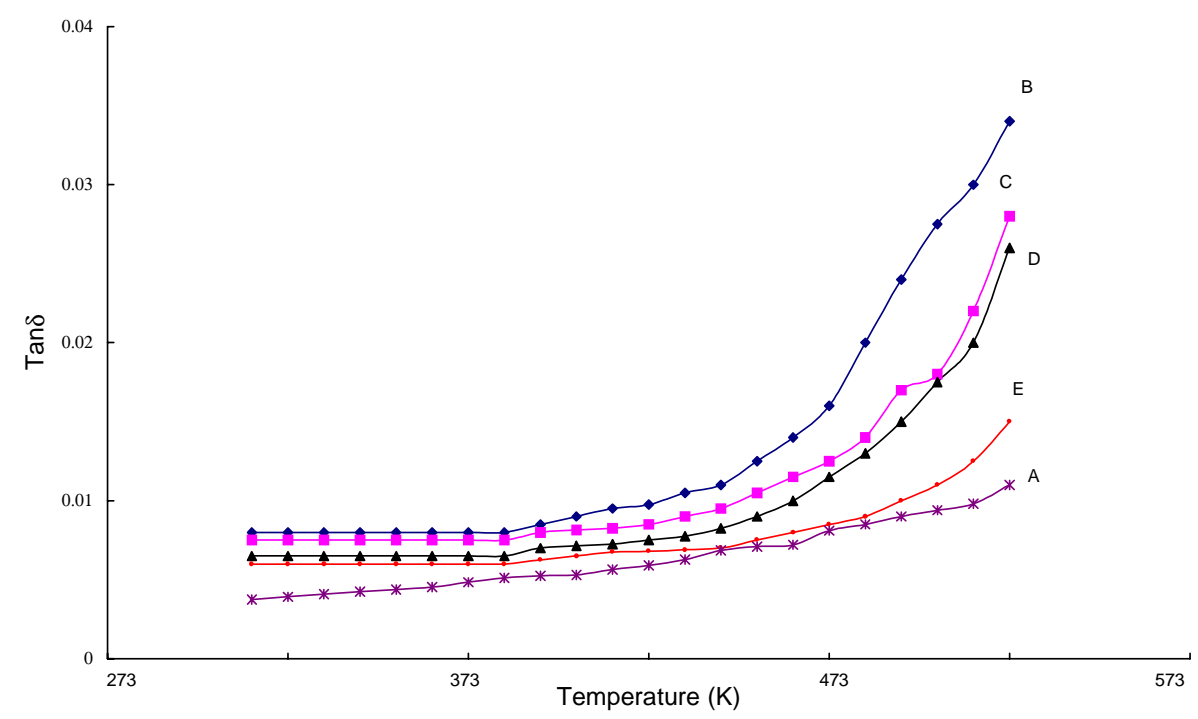

Figure 6. Variation of dielectric loss with temperature at $10 \mathrm{kHz}$ for $\mathrm{NaF}-\mathrm{B}_{2} \mathrm{O}_{3}$ glasses doped with different transition metal oxides: A-Pure, B-CuO, C- $\mathrm{V}_{2} \mathrm{O}_{5}, \mathrm{D}-\mathrm{TiO}_{2}$ and $\mathrm{E}-\mathrm{MnO}_{2}$. 
thus resulting in large proportions of space charge polarization, which ultimately causes larger increase of $\varepsilon$ and $\tan \delta$ values as observed when compared with other glasses.

It is interesting to find that the nature of variation of $\varepsilon$ and $\tan \delta$ with temperature is similar. A plot of $\log (\Delta \varepsilon)$ against $1 / T$ (where $\Delta \varepsilon$ is the difference between dielectric constant at any temperature $T$ and that at room temperature) at different frequencies for glass $\mathrm{B}$ is shown in figure 9; the graphs are straight lines having about the same slope for all the frequencies in the high temperature region. The computed activation energy is $0.41 \mathrm{eV}$. This value is practically the same as the activation energy for a.c. conduction in the same temperature region in these glasses. This seems to suggest that the charge carriers responsible for change in $\varepsilon$ and $\sigma$ with temperature in this temperature range are the same. A similar analysis was also carried out on the other glasses and found to yield similar results. Further, this activation energy too is found to decrease from glass E to B (table 3).
In general the a.c. conductivity of the amorphous material where charge carriers experience an approximately random potential energy on diffusing, is found to obey the equation (Austin and Mott 1969):

$$
\sigma(\omega)=A \omega^{\mathrm{s}}
$$

(where $A$ is a constant and $\omega$ the frequency) with the frequency exponent $s<1$ up to the frequency of $1 \mathrm{MHz}$. Though various models have been developed to interpret the a.c. conduction mechanism in the glasses, we have first attempted to explain a.c. conduction in the present $\mathrm{NaF}-\mathrm{B}_{2} \mathrm{O}_{3}$ glasses on the basis of quantum mechanical tunneling (QMT) model.

According to QMT model, only those pairs of carriers separated by hopping distance $R_{\mathrm{i}}$, given by:

$$
R_{\mathrm{i}}=(1 / 2 \alpha) \ln \left(\frac{v_{\mathrm{ph}}}{\omega}\right) \text {, }
$$

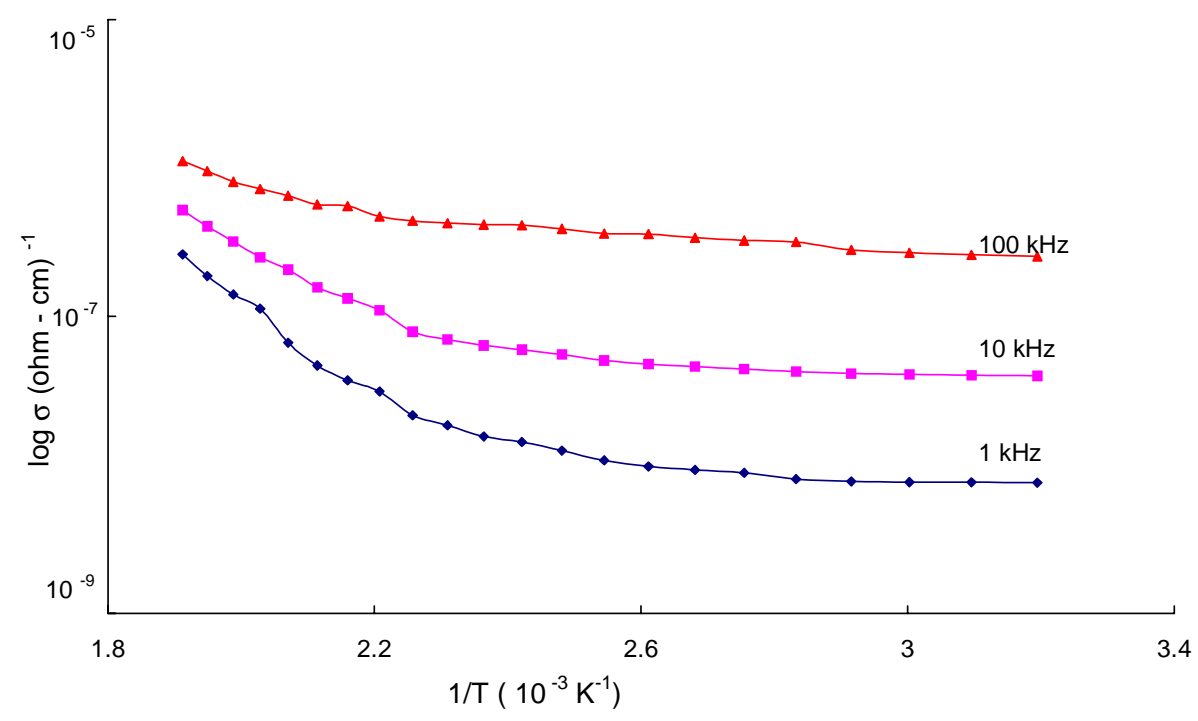

Figure 7. Variation of a.c. conductivity with $1 / T$ at different frequencies for $\mathrm{NaF}-\mathrm{B}_{2} \mathrm{O}_{3}$ glasses doped with $\mathrm{V}_{2} \mathrm{O}_{5}$ (glass $\mathrm{C}$ ).

\begin{tabular}{|c|c|c|c|c|c|c|c|}
\hline \multirow[b]{2}{*}{ Glass } & \multicolumn{3}{|c|}{$N\left(E_{\mathrm{F}}\right)$ in $\left(10^{22}, \mathrm{eV}^{-1} / \mathrm{cm}^{3}\right)$} & \multicolumn{3}{|c|}{ A.E. $(e V)$} & \multirow[b]{2}{*}{$\begin{array}{l}\text { Breakdown strength } \\
\qquad(\mathrm{kV} / \mathrm{cm})\end{array}$} \\
\hline & $\begin{array}{l}\text { Austin and Mott } \\
\qquad(1969)\end{array}$ & $\begin{array}{l}\text { Butcher and Hyden } \\
\text { (1977) }\end{array}$ & $\begin{array}{l}\text { Pollak } \\
(1971)\end{array}$ & $S_{\text {exp }}$ & $\sigma_{\text {a.c. }}$ & $\Delta \varepsilon$ & \\
\hline A & - & - & - & - & $0 \cdot 98$ & 0.97 & $12 \cdot 10$ \\
\hline $\mathrm{B}$ & $6 \cdot 45$ & $2 \cdot 70$ & $6 \cdot 50$ & $0 \cdot 90$ & $0 \cdot 42$ & 0.41 & $6 \cdot 20$ \\
\hline C & 4.95 & $2 \cdot 00$ & 4.99 & 0.88 & $0 \cdot 70$ & 0.71 & 8.44 \\
\hline $\mathrm{D}$ & $4 \cdot 49$ & $1 \cdot 87$ & $4 \cdot 50$ & $0 \cdot 85$ & $0 \cdot 81$ & $0 \cdot 80$ & $8 \cdot 74$ \\
\hline $\mathrm{E}$ & $3 \cdot 29$ & $1 \cdot 37$ & $3 \cdot 30$ & $0 \cdot 81$ & $0 \cdot 90$ & $0 \cdot 91$ & $11 \cdot 73$ \\
\hline
\end{tabular}

Table 3. Data on a.c. conductivity of $\mathrm{NaF}-\mathrm{B}_{2} \mathrm{O}_{3}$ glasses.

The dielectric breakdown strength for pure glass (glass A) is determined to be $12 \cdot 1 \mathrm{kV} / \mathrm{cm}$; the value of breakdown strength increases from glass B to A (table 3). 


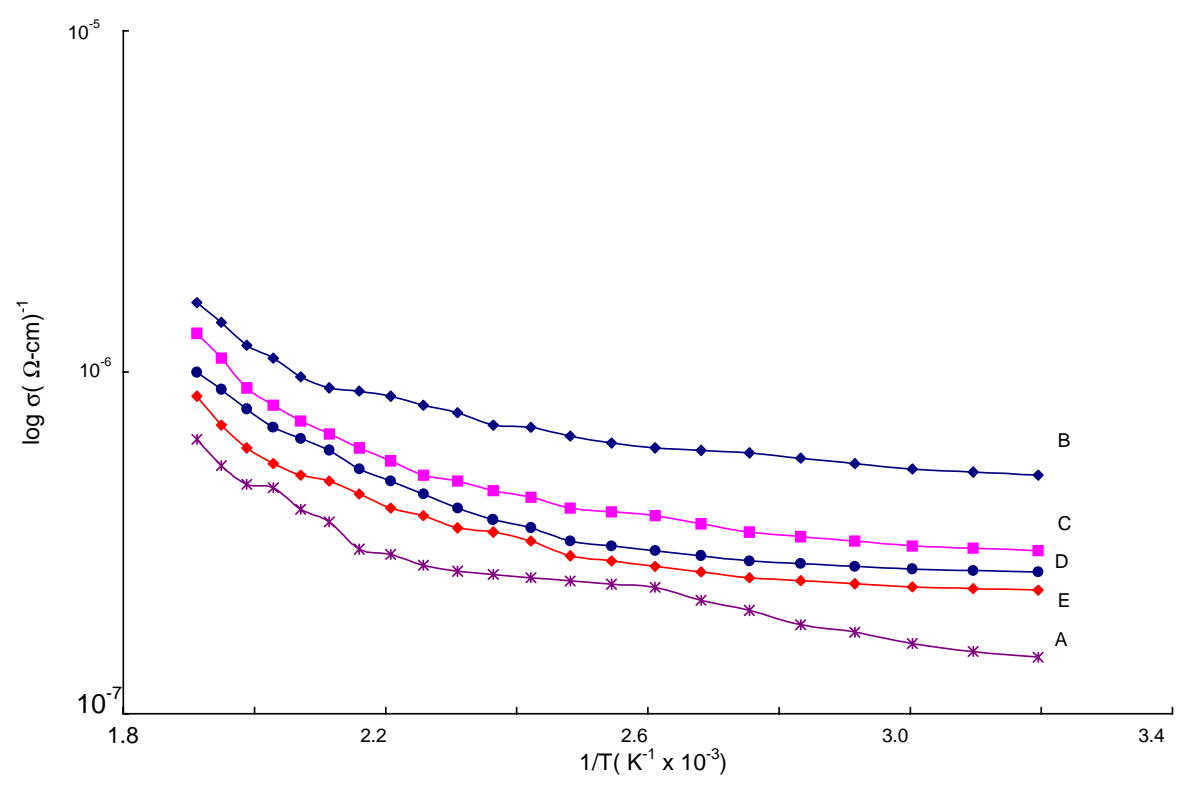

Figure 8. Comparison of variation of a.c. conductivity with $1 / T$ at $100 \mathrm{kHz}$ for $\mathrm{NaF}-$ $\mathrm{B}_{2} \mathrm{O}_{3}$ glasses doped with different transition metal oxides: A-Pure, B-CuO, C- $\mathrm{V}_{2} \mathrm{O}_{5}$, $\mathrm{D}-\mathrm{TiO}_{2}$ and $\mathrm{E}-\mathrm{MnO}_{2}$.

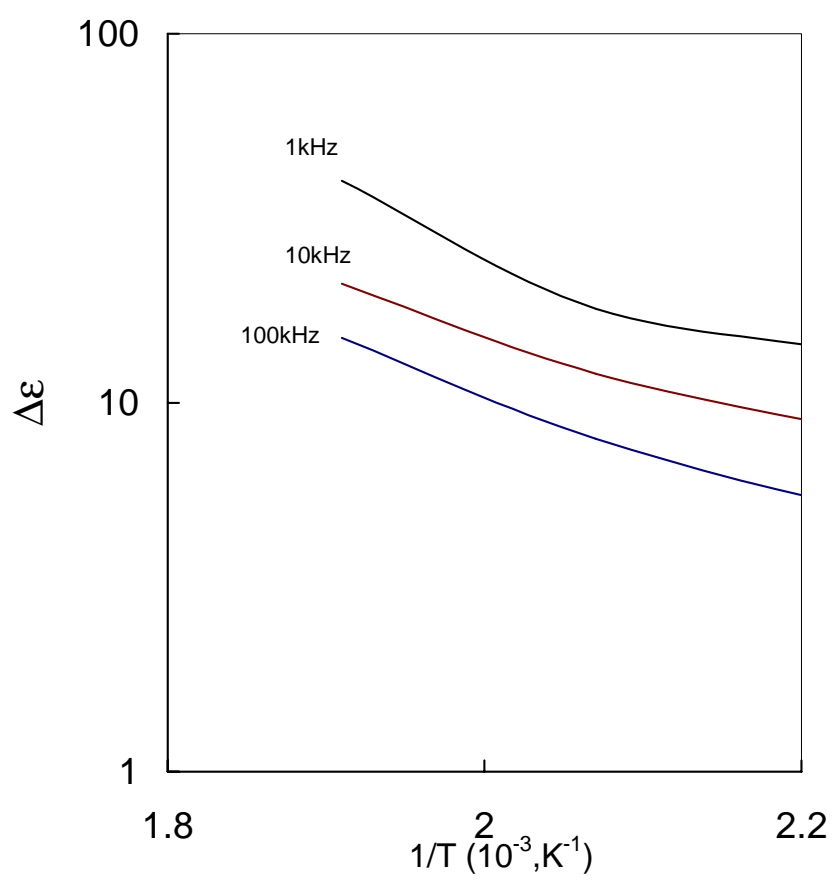

Figure 9. $\log \Delta \varepsilon$ vs $1 / T$ at different frequencies for $\mathrm{CuO}$ doped $\mathrm{NaF}-\mathrm{B}_{2} \mathrm{O}_{3}$ glasses (glass $\mathrm{B}$ ).

contribute significantly to the conduction. With this, the equation for a.c. conductivity due to quantum mechanical tunneling is given by:

$$
\sigma(\omega)=\frac{\eta e^{2} K T}{3}\left[N\left(E_{\mathrm{F}}\right)\right]^{2} \alpha^{-5} \omega\left[\ln \frac{v_{\mathrm{ph}}}{\omega}\right]^{4},
$$

where $N\left(E_{\mathrm{F}}\right)$ is the density of the energy states near the Fermi level, $\alpha$ the electronic wave function decay constant, $v_{\mathrm{ph}}$ the phonon frequency and $\eta$ is a constant and its value is given by: $\eta=\pi / 3$ (Austin and Mott 1969), $=3.66 \pi^{2} / 6$ (Butcher and Hyden 1977), $=\pi^{4} / 96$ (Pollak 1971).

The frequency component $s$ is defined as:

$$
s=\frac{\partial(\ln \sigma)}{\partial(\ln \omega)}
$$

Substitution of (4) into (5) results in

$$
s=1-\frac{4}{\ln \left(1 / \omega \tau_{0}\right)}
$$

Thus the quantum mechanical tunneling of a carrier through the potential barrier between the sites separated by a distance $R_{\mathrm{i}}$ demands that ' $s$ ' should be temperature independent.

From the plots of $\log \sigma(\omega)$ vs $\log \omega$ for these glasses at a temperature of $373 \mathrm{~K}$, we have obtained the experimental values of $s$ (table 3 ); further graphs obtained are straight lines indicating that the exponent $s$ is independent of frequency, hence it is not fully consistent with (6). Perhaps, the more accurate model for a.c. conduction in which $s$ is less dependent on frequency (as observed) for a.c. conduction in $\mathrm{NaF}-\mathrm{B}_{2} \mathrm{O}_{3}$ glasses is the correlated barrier hopping (CBH) model (Elliot 1987) in which the height of the potential barrier is correlated with inter site separation. According to this model 


$$
s=1-\frac{6 K T}{E_{0}-K T \ln \left(1 / \omega \tau_{0}\right)},
$$

where $E_{0}$ is the optical band gap. According to (6), the value of $s$ changes by 0.07 for a frequency change of $10^{2}-10^{6} \mathrm{~Hz}$, whereas this change is only 0.003 as per (7) for the same change in the frequency for a fixed optical band gap. Hence (7) can be assumed to give more accurate value of $s$ than (6) for the present glasses and the $\mathrm{CBH}$ model can be assumed to be more appropriate than the QMT model for a.c. conduction in these glasses. However, further analysis on a.c. conduction for these glasses is carried out on the basis of QMT model for the lack of accurate value of optical band gap $E_{0}$ at different temperatures. The experimental values of $s$ obtained for these glasses are presented in table 3 along with the other important data on a.c. conduction.

Among various mechanisms for conduction (like band conduction, conduction in extended states, conduction in localized states near the band edge and conduction in the localized states near the Fermi level) in the amorphous materials, the conduction in the localized states near the Fermi level occurs when a.c. conductivity is nearly temperature independent and varies linearly with frequency. The conduction in present $\mathrm{NaF}-\mathrm{B}_{2} \mathrm{O}_{3}$ glasses in the low temperature region (up to $400 \mathrm{~K}$ ) can safely be attributed to take place by this mechanism. The value of $N\left(E_{\mathrm{F}}\right)$, i.e. the density of energy states near Fermi level, for a frequency of $10^{4} \mathrm{~Hz}$ and at $373 \mathrm{~K}$, taking $\alpha$ (determined by plotting $\log \sigma$ against $R$ as per the relation $\left.\sigma \propto e^{-2 \alpha R_{\mathrm{i}}}\right) \approx 2.27 \AA^{-1}$ and $v_{\mathrm{ph}} \sim 5 \times 10^{12} \mathrm{~Hz}$ is calculated using (4), with value of numerical constant $\eta$ suggested by different investigators and presented in table 3 . The value of $N\left(E_{\mathrm{F}}\right)$ is found to decrease from glass $\mathrm{B}$ to $\mathrm{E}$. Further the range of $N\left(E_{\mathrm{F}}\right)$ values obtained were $\approx 10^{22} \mathrm{eV}^{-1} / \mathrm{cm}^{3}$. Such values of $N\left(E_{\mathrm{F}}\right)$ suggest the localized states near the Fermi level (Elliot 1987). The increase in the conductivity (decrease in activation energy) from glass $B$ to $E$ can be understood due to the increase in the density of these energy states.

A similar conclusion can also be drawn when we look into the glass transition temperatures of these glasses. The glass transition temperature $T_{\mathrm{g}}$ is observed to increase from glass B to E (table 1) and further found to fit into the relation (Tanaka 1985)

$$
\ln T_{\mathrm{g}} \approx 1 \cdot 6 Z+2 \cdot 3 \text {, }
$$

where $Z$ is the average coordination number. This equation indicates that smaller the value of $T_{\mathrm{g}}$, lower is the value of average coordination number $Z$. The fact that low value of the glass transition temperature (table 1) observed for $\mathrm{CuO}$ doped glasses indicates that the $\mathrm{Cu}^{2+}$ ions in $\mathrm{NaF}-\mathrm{B}_{2} \mathrm{O}_{3}$ glass network are loosely bound and hence giving high conductivity (or yielding low activation energy) when compared with the other samples. This may also explain why there is a successive decrease in the conductivity (or increase in the activation energy for conduction) from glass $\mathrm{B}$ to $\mathrm{E}$. When the dielectric is placed in the electric field, the heat of dielectric loss is liberated. If the applied field is an alternating field, the specific dielectric loss i.e. the loss per unit volume of the dielectric, is given by (Tareev 1979)

$$
\rho_{1}=E^{2} \omega \varepsilon \varepsilon_{0} \tan \delta \mathrm{W} / \mathrm{m}^{3},
$$

here $E$ is the electric field applied. This equation indicates that the higher the values of $\varepsilon \tan \delta$ of the glass at a given frequency, the higher are the losses. In a dielectric across which the voltage is applied, heat is liberated, the temperature of the dielectric then rises and the loss increases still more. The dielectric breakdown strength is in fact inversely proportional to the specific dielectric loss represented by (9).

Recollecting the data on breakdown strengths of NaF$\mathrm{B}_{2} \mathrm{O}_{3}$ glasses, as seen earlier, the rate of increase of $\varepsilon \tan \delta$ with temperature is highest for glass $\mathrm{B}$ and minimum for pure glass (glass A). Though the breakdown strengths are actually determined at room temperature, the heat liberated during the breakdown rises the temperature of the glass and hence rises the $\varepsilon \tan \delta$ value. Since the rate of increase of $\varepsilon \tan \delta$ with temperature is highest for glass B, the breakdown strength is lower when compared with the other glasses. Thus the experiments on the dielectric breakdown strength of $\mathrm{NaF}-\mathrm{B}_{2} \mathrm{O}_{3}$ glasses reveal that there is a large concentration of defects (such as dangling bonds and point defects) in $\mathrm{CuO}$ doped glasses when compared with the other glasses. Further, it may be noted here that among all the metallic ions doped in these glasses $\mathrm{Cu}^{2+}$ ion has the highest ionic radius $(0.072 \mathrm{~nm})$ which may be the reason for the presence of large concentration of defects in these glasses.

\section{Conclusions}

From the results of various electrical measurements on $\mathrm{NaF}-\mathrm{B}_{2} \mathrm{O}_{3}$ glasses doped with $\mathrm{CuO}, \mathrm{V}_{2} \mathrm{O}_{5}, \mathrm{TiO}_{2}$ and $\mathrm{MnO}_{2}$, it is observed that there is a larger increase in the rates of $\varepsilon \tan \delta, \sigma_{\text {a.c. }}$ with temperature and decrease in the values of dielectric breakdown strength and activation energy for a.c. conduction for the glasses containing different transition metal ions.

\section{References}

Ahmed A A and Abd-Elshafi N 1998 Indian J. Pure \& Appl. Phys. 36335

Austin I G and Mott N F 1969 Adv. Phys. 18657

Butcher P and Hyden K J 1977 Philos. Mag. 36657

Elliot S R 1987 Adv. Phys. 36135

Ghosh A and Chauduri R K 1996 J. Non-Cryst. Solids 83151

Khalifa F A and Elhadi A A 1996 Indian J. Pure \& Appl. Phys. 34201 
Kumar A V R and Veeraiah N 1999 J. Mater. Sci. Lett. 18475

Mallawany R El 1994 Mater. Chem. Phys. 37157

Nageswara Rao K and Veeraiah N 2000 Indian J. Phys. A B74 37

Pollak M 1971 Philos. Mag. 23519

Ramana M V and Sastry G S 1989 Phys. Status Solidi B116 K206

Ravi Kumar V and Veeraiah N 1995 Phys. Status Solidi A47 601

Ravi Kumar V and Veeraiah N 1998 J. Phys. Chem. Solids 5991
Ravi Kumar V, Veeraiah N and Buddudu S 1997 J. Phys. III 70951

Sagar K D, Kistaiah P, Rao B A, Murthy K S N and Veeraiah N 1998 Indian J. Pure \& Appl. Phys. 36467

Sagar K D, Kistaiah P, Rao B A, Murthy K S N and Veeraiah N 1999 J. Mater. Sci. Lett. 1855

Sridhar B, Indira B and Bhatnagar A K 1995 Indian J. Pure \& Appl. Phys. 33253

Tanaka K 1985 Solid State Commun. 54867

Tareev B 1979 Physics of dielectric materials (Moscow: MIR Publishers) 